\title{
EFEKTIVITAS PENGGUNAAN OIL SKIMMER DALAM UPAYA PENANGANAN TUMPAHAN MINYAK DI PELABUHAN PERIKANAN PANTAI (PPP) TEGALSARI KOTA TEGAL
}

\author{
The effectiveness of the use of Oil Skimmer in Efforts Handling Oil Spill \\ in Tegalsari Fishing Port, Tegal
}

\section{Fajar Sidik Pamungkas, Haeruddin*) dan Siti Rudiyanti}

Program Studi Manajemen Sumberdaya Perairan

Fakultas Perikanan dan Ilmu Kelautan, Universitas Diponegoro

Jl. Prof. Soedarto, SH, Tembalang, Semarang, Jawa Tengah - 50275, Telp/Fax. +6224 7474698

Email : Fajarpamungkas16@gmail.com

\begin{abstract}
ABSTRAK
Pelabuhan Perikanan Pantai (PPP) Tegalsari, terletak di Kota Tegal, Jawa Tengah. Pelabuhan ini memiliki luas mencapai 16,3 Ha, dengan luas kolam pelabuhannya yaitu $32.400 \mathrm{~m}^{2}=3,24 \mathrm{Ha}$ dan dapat menampung hingga 124 unit kapal penangkap ikan dengan ukuran 5-30 GT. Kondisi kapal yang tidak sesuai dengan standar yang telah ditetapkan, menjadi penyebab utama masuknya limbah minyak ke perairan, sehingga memerlukan penanganan khusus untuk menanggulangi tingkat pencemaran limbah minyak. Perlu adanya water treatment sebagai upaya untuk mengurangi beban pencemar di perairan antara lain dengan menggunakan Oil Skimmer. Penelitian ini bertujuan untuk mengetahui kandungan minyak pada saat sebelum diolah dan setelah diolah dengan Oil Skimmer, serta untuk mengetahui tingkat efektivitas dari penggunaan Oil Skimmer. Penelitian ini dilaksanakan pada bulan September 2016 di PPP Tegalsari, Kota Tegal. Metode yang digunakan adalah metode penelitian secara observatif dengan pengamatan secara langsung di lapangan dan pengambilan sampel dengan teknik purpossive sampling dan uji laboratorium untuk menganalisis kandungan minyak dan lemak dengan metode gravimetric sesuai SNI 06-6989.10-2004. Analisa data menggunakan Uji $\mathrm{t}$ - Berpasangan untuk mengetahui apakah ada perbedaan kandungan minyak sebelum dan setelah diolah dengan Oil Skimmer. Hasil penelitian menunjukkan bahwa Oil Skimmer mampu mereduksi kandungan minyak di perairan tercemar dari sebelum diolah dengan Oil Skimmer rata-rata berkisar antara 549 mg/1 - $5045 \mathrm{mg} / 1 \mathrm{menjadi} 91,25 \mathrm{mg} / \mathrm{l}-173 \mathrm{mg} / \mathrm{l}$ setelah diolah dengan Oil Skimmer, dengan rata-rata tingkat efektivitas mencapai 58,5\% - 97\%. Hasil analisa statistik dengan uji $\mathrm{t}$ - berpasangan $(\alpha 0,05)$ didapatkan nilai $\mathrm{t}$ yaitu $0,004 \leq 0,05$ hal ini menunjukkan bahwa kandungan minyak sebelum diolah dengan Oil Skimmer memiliki perbedaan yang signifikan dengan kandungan minyak setelah diolah dengan Oil Skimmer.
\end{abstract}

Kata Kunci : Cemaran Minyak, Oil Skimmer, Oil Water Separator, Efektivitas, Pelabuhan Perikanan Pantai Tegalsari. ABSTRACT

Tegalsari fishing port is located in Tegal, Central Java. This port has an area of 16.3 hectares, with its harbor swimming area is 32,400 $\mathrm{m2}=3.24$ hectares and can accommodate up to 124 units of fishing vessels with a size of 5-30 GT. The condition of the ship that does not comply with the standards that have been set, the main cause of the influx of waste oils into waters, thus requiring special handling to cope with the level of contamination of waste oil. The need for water treatment as a means to reduce the burden of pollutants in water by using Oil Skimmer. This study aims to determine the oil content at the moment before it is processed and after treatment by the Oil Skimmer, and to investigate the effectiveness of the use of Oil Skimmer. This research was conducted in September 2016 in PPP Tegalsari, Tegal. The method used is a method in observational studies with direct observation in the location and sampling with purposive technique sampling and laboratory testing to analyze the content of oils and fats by gravimetric method in accordance with SNI 06-6989.10-2004. Data were analyzed using t tests - Pairwise to determine whether there are differences in oil content before and after treatment by the Oil Skimmer. The results showed that the Oil Skimmer is able to reduce the oil content in the polluted waters of Oil Skimmer before it is processed with an average ranging between $549 \mathrm{mg} / \mathrm{l}-5045 \mathrm{mg} / \mathrm{l}$ to $91.25 \mathrm{mg} / \mathrm{l}$ - $173 \mathrm{mg} / \mathrm{l}$ after treatment by Oil Skimmer, with an average effectiveness rate was 58.5\% - 97\%. Statistical analysis by t test-pairs ( $\alpha 0.05)$ were obtained, namely $0,004 t v a l u e \leq$ 0.05 it indicates that the oil content before it is processed by the Oil Skimmer has significant differences with oil content after treatment by Oil Skimmer.

Keywords: $\quad$ Oil Pollution, Oil Skimmer, Oil Water Separator, Effectiveness, Tegalsari Port Fishery.

*) Penanggunga jawab 


\section{PENDAHULUAN}

Minyak merupakan salah satu sumber pencemar dalam perairan, yang disebabkan karena berbagai hal mulai dari eksplorasi minyak bumi, pengilangan minyak, kecelakaan transportasi, kebocoran pipa, ataupun pembuangan air buangan kamar mesin dan kapal lainnya (Nuryatini, 2010). Cemaran minyak ini dapat menimbulkan polusi terhadap perairan dan laut yang berdampak pada turunnya daya dukung lingkungan yang berdampak pada terganggunya keberlangsungan hidup organisme dalam perairan tersebut. Menurut Peraturan Menteri Nomor 21 Tahun 2010 tentang Perlindungan Lingkungan Maritim, disebutkan bahwa kegiatan diatas kapal dapat menyumbang bahan pencemar diantaranya; minyak, bahan cair beracun, muatan bahan berbahaya dalam bentuk kemasan, kotoran, sampah, udara, air ballast, dan atau barang dan bahan berbahaya bagi lingkungan yang ada di kapal. Oleh sebab itu, setiap awak kapal wajib melakukan pencegahan dan menanggulangi pencemaran yang bersumber dari kapalnya.

Salah satu upaya yang dapat dilakukan yaitu dengan menggunakan OWS (Oil Water Separator) atau pemisah minyak yang diharapkan akan lebih efektif dalam mencegah pencemaran minyak. Sistem kerja alat ini adalah dengan memisahkan antara partikel minyak dan air. Air laut dihisap kedalam OWS yang kemudian partikel minyak dari perairan dipisahkan sehingga sesuai baku mutu air yang ditetapkan. Berbagai modifikasi alat OWS telah dilakukan untuk menangani beberapa kasus pencemaran minyak di perairan. Kurangnya kesadaran para nelayan akan pentingnya menjaga kelestarian lingkungan merupakan faktor utama pemicu munculnya pencemaran tumpahan minyak di perairan. Penggunaan kapal yang tidak dilengkapi dengan OWS mengakibatkan pencemaran di perairan semakin meningkat, untuk menangani kasus pencemaran tumpahan minyak diatas perairan, OWS dimodifikasi menjadi Oil skimmer, yaitu dengan penambahan alat vakum sebagai penghisap contoh air laut yang tercemar minyak, dan kapal atau Boat yang berfungsi sebagai alat penggerak oil skimmer.

Alat Oil Skimmer telah diuji coba sebelumnya oleh Balai Besar Pengembangan Penangkapan Ikan (BBPPI) Semarang. BBPPI Semarang mencoba menerapkan penggunaan Oil Skimmer di PPP Tegalsari, Kota Tegal. Seperti kita ketahui, Kota Tegal merupakan salah satu kota di Jawa Tengah yang memiliki potensi sumberdaya perikanan yang cukup besar. Hal ini dapat dilihat dari data Badan Pusat Statistik (BPS) Kota Tegal 2013, yang mengatakan bahwa produksi sektor perikanan kota Tegal yang mecapai 25.875 ton per tahun, yaitu tertinggi ketiga setalah Kota Rembang dan Kota Pekalongan. Kota Tegal memiliki 2 pelabuhan, yaitu Pelabuhan Tegal dan Pelabuhan Perikanan Pantai (PPP) Tegalsari Kota Tegal. Pelabuhan Tegal sendiri keberadaannya saat ini sudah tidak aktif atau tidak difungsikan kembali untuk kegiatan perikanan karena berbagai hal, dan sekarang kegiatan perikanan di Kota Tegal berlangsung di Pelabuhan Perikanan Pantai (PPP) Tegalsari, dimana pelabuhan tersebut memiliki skala yang cukup besar dibanding Pelabuhan Tegal. Banyak kapal penangkap ikan yang berlabuh di pelabuhan tersebut, karena lokasinya dekat dengan TPI (Tempat Pelelangan Ikan) yang memudahkan proses distribusi hasil tangkapan dari laut. Tingginya intensistas aktifitas kapal penangkap ikan yang ada di pelabuhan memungkinakan akan berdampak kepada kelestarian lingkungan perairan di area pelabuhan. Dampak negatif dari adanya aktifitas kapal yang tinggi adalah pencemaran minyak yang merupakan hasil buangan dari kapal penangkap ikan. Keberadaan limbah minyak dapat mencemari perairan, karena sifat minyak yang dapat menghalangi sinar matahari untuk masuk kedalam perairan untuk proses fotosintesis tumbuhan air atau alga seperti fitoplankton yang merupakan sumber makanan utama bagi organisme periaran. Selain itu keberadaan minyak di atas perairan juga menghalangi masuknya kandungan oksigen terlarut untuk proses respirasi bagi organisme perairan. Oleh karena itu perlu penanganan yang tepat dengan menggunakan oil skimmer agar lebih efektif dalam mencegah dan menangani pencemaran tumpahan minyak di perairan.

Tujuan dari pelaksanaan penelitian ini adalah sebagai berikut :

1. Mengetahui konsentrasi minyak di perairan Pelabuhan Perikanan Pantai (PPP) Tegalsar Kota Tegal, terutama pada lokasi sampling, sebelum dan sesudah diolah dengan Oil skimmer;

2. Mengetahui tingkat efektivitas penggunaan Oil Skimmer di Perairan Pelabuhan Perikanan Pantai (PPP) Tegalsari Kota Tegal dalam upaya penanganan pencemaran tumpahan minyak.

\section{MATERI DAN METODE}

Materi yang digunakan dalam penelitian ini adalah kandungan minyak total dari perairan Pelabuhan Perikanan Pantai (PPP) Tegalsari, Kota Tegal sebelum dan sesudah dilakukan treatment pada Oil skimmer. Alat dan Bahan yang digunakan dalam penelitian ini adalah sebagai berikut :

Tabel 1. Alat Penelitian

\begin{tabular}{clcl}
\hline No & Nama Alat & Ketelitian & \multicolumn{1}{c}{ Fungsi } \\
\hline 1 & Oil Skimmer & - & Sebagai alat untuk menanggulangi pencemaran tumpahan minyak \\
2 & Botol Sampel & $500 \mathrm{ml}$ & sebagai tempat contoh air laut yang tercemar minyak \\
3 & Beaker Glass & $250 \mathrm{ml}$ & $\begin{array}{l}\text { sebagai tempat contoh air untuk uji laboratorium } \\
\text { sebagai alat untuk memisahkan ekstrak minyak dalam uji }\end{array}$ \\
4 & Corong Pemisah & $250 \mathrm{ml}$ & $\begin{array}{l}\text { laboratorium } \\
\text { sebagai alat untuk menyaring contoh air sebelum dilakukan uji }\end{array}$ \\
5 & Corong Filtrasi & - & $\begin{array}{l}\text { laboratorium } \\
\text { sebagai alat ukur volume contoh air }\end{array}$ \\
6 & Gelas Ukur & $1000 \mathrm{ml}$ &
\end{tabular}


Efektivitas Penggunaan Oil Skimmer dalam Upaya Penanganan Tumpahan Minyak di PPP Tegalsari Kota Tegal

$\begin{array}{clcl}7 & \text { Desikator } & - & \begin{array}{l}\text { sebagai alat untuk menghilangkan kadar air pada beaker glass } \\ \text { setelah proses pemanasan }\end{array} \\ 8 & \text { Timbangan digital } & 0.01 \mathrm{gr} & \begin{array}{l}\text { sebagai alat untuk menimbang berat beaker glass sebelum dan } \\ \text { sesudah ekstraksi }\end{array} \\ 9 & \text { Hot Plate } & - & \begin{array}{l}\text { sebagai alat untuk memanaskan proses ekstraksi } \\ \text { sebagai alat untuk memindahkan beaker glass }\end{array} \\ 10 & \text { Penjepit } & - & \begin{array}{l}\text { sebagai alat untuk menghilangkan kadar air pada beaker glass } \\ \text { sebelum digunakan dalam uji laboratorium }\end{array} \\ 11 & \text { Oven } & \text { 120 C } & \end{array}$

Sumber : Penelitian September 2016

Tabel 2. Bahan Penelitian

\begin{tabular}{|c|c|c|c|}
\hline No & Nama Bahan & Jumlah & Fungsi \\
\hline 1 & $\begin{array}{l}\text { Contoh air laut yang tercemar } \\
\text { limbah minyak }\end{array}$ & $500 \mathrm{ml}$ & sebagai bahan utama untuk uji laboratorium \\
\hline 2 & n-Hexane & $30 \mathrm{ml}$ & sebagai pelarut organik \\
\hline 3 & Kertas Label & - & sebagai penanda \\
\hline 4 & Tissue & - & untuk membersihkan alat \\
\hline
\end{tabular}

Sumber : Penelitian September 2016

Metode penelitian yang digunakan adalah metode penelitian observatif dengan melakukan pengamatan di lapangan secara langsung dengan teknik sampling secara acak pada perairan yang terdapat limbah minyak. Tujuan dari teknik sampling ini yaitu untuk mengamati kondisi perairan dengan mengambil sampel air atau limbah minyak sebelum dan sesudah diproses dengan Oil skimmer, untuk kemudian dilakukan uji kandungan minyak di laboratorium untuk memperoleh nilai atau data. Selanjutnya data tersebut diolah untuk dianalisis lebih lanjut untuk memperoleh nilai efektivitas dari alat Oil skimmer.

Contoh air laut yang tercemar atau terkontaminasi minyak diambil pada 3 titik, kemudian pada masing-masing sampel dilakukan analisa contoh air laut sebelum dan sesudah diolah dengan oil skimmer dan dilakukan dengan 2 kali pengambilan. Titik sampling ditentukan dengan menggunakan GPS. Pengambilan contoh air menggunakan penampung sementara atau botol sampel kemudian melakukan homogenisasi contoh air, selanjutnya memasukkan ke dalam botol sampel yang sudah dibilas sebelumnya sebanyak $500 \mathrm{ml}$ sesuai dengan metode pengajian minyak pada SNI 06-6989.102004. Pengambilan contoh air laut di perairan ini dilakukan menurut prosedur SNI 6989.59:2008 tentang Air dan Limbah Cair - Bagian 59 : Metode Pengambilan Sampel Limbah Cair. Skema Pengambilan contoh air laut yang tercemar limbah minyak dapat dilihat pada gambar 1 dan 2 sebagai berikut :

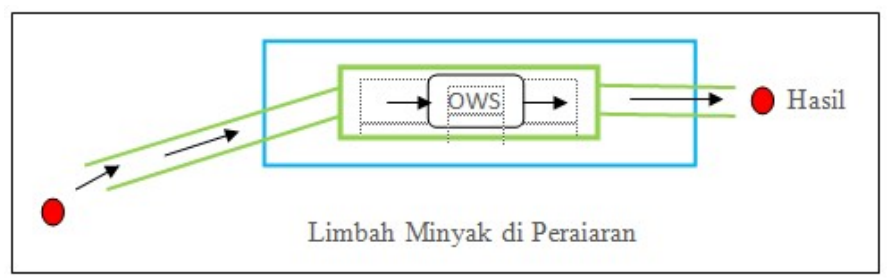

Keterangan :

Gambar 1. Skema Pengambilan Sampel
: Kapal
: Oil Skimmer
○ : Titik sampling 


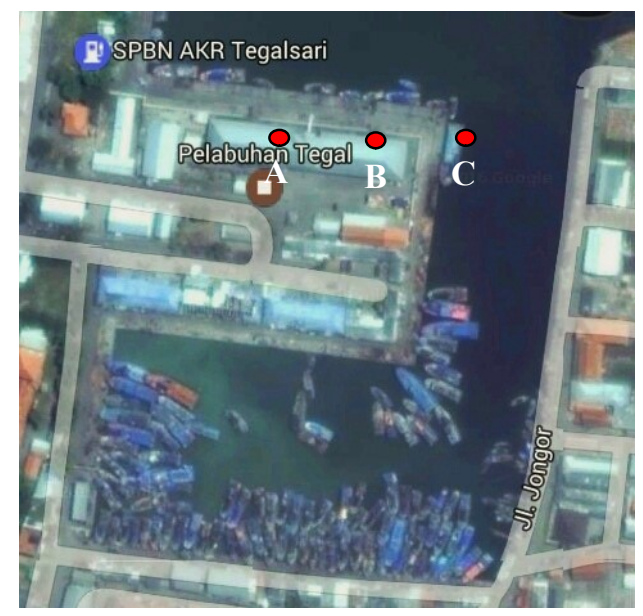

Keterangan :

Gambar 2. Pengambilan titik samling
○ : Titik sampling
A : Titik sampling pertama
B : Titik sampling kedua
C : Titik sampling ketiga

Tahap pengujian pada penelitian ini, meliputi uji kandungan minyak dalam limbah cair menggunakan metode gravimetri (SNI 06-6989.10-2004), baik sebelum dan sesudah pengolahan pada Oil skimmer untuk memunculkan perhitungan nilai efektivitas dalam analisa data.

Setelah konsentrasi minyak pada contoh air laut diketahui, kemudian dilakukan perhitungan statistik dengan menggunakan uji t berpasangan dengan subjek yang sama namun mengalami dua perlakuan berbeda. Menurut Soenarno (2011), contoh yang berpasangan diartikan sebagai sebuah contoh dengan subjek yang sama, namun mengalami dua perlakuan atau pengukuran yang berbeda, dalam penelitian ini yaitu contoh sebelum dan setelah diolah dengan oil skimmer. Uji t berpasangan dilakukan untuk mengetahui bagaimana pengaruh pada setiap variabel bebas (sebelum dan setelah diolah oil skimmer) terhadap variabel terikat (limbah minyak).

Penarikan kesimpulan ditentukan oleh $\alpha(0,05)$ dimana tingkat kemungkinan (probability) data tersebut memiliki perbedaan adalah $5 \%$ dengan pendugaan atau hipotesa sebagai berikut :

Ho : Kandungan minyak sebelum diolah dengan oil skimmer tidak memiliki perbedaan dengan kandungan minyak setelah diolah dengan oil skimmer $(\mathrm{t} \geq \alpha)$.

H1 : Kandungan minyak sebelum diolah dengan oil skimmer memiliki perbedaan dengan kandungan minyak setelah diolah dengan oil skimmer $(\mathrm{t} \leq \alpha)$.

Data hasil uji kandungan minyak dan lemak, kemudian dianalisis nilai persen efektivitas Oil Skimmer (Fahrurrozie et al., 2010 dalam Setiawan, 2014), dengan rumus :

Dimana:

$$
\eta=\frac{\text { VMAw }- \text { VMAk }}{\text { VMAw }} \times 100 \%
$$

$\begin{array}{lll}\text { Efektifitas }(\eta) & =\text { Efektivitas }(\%) & \text { VMAw } \\ \text { VMAk } & =\text { Kandungan miyak akhir }(\mathrm{mg} / \mathrm{l})\end{array}$

Penentuan nilai efektifitas dalam penggunaan oil skimmer untuk mereduksi kandungan minyak pada contoh air laut, merupakan nilai yang diperoleh dari perbandingan antara nilai kandungan minyak sebelum dan setelah diolah dengan oil skimmer, sehingga dengan pedoman tersebut maka akan muncul kesimpulan apakah oil skimmer sudah efektif atau belum dalam menanggulangi pencemaran tumpahan minyak di perairan. Menurut Wibowo (2014) efektifitas alat pemisah limbah cair berminyak merupakan nilai perbandingan antara volume miyak akhir dengan volume minyak awal.

\section{HASIL DAN PEMBAHASAN}

Lokasi penelitian berada di Pelabuhan Perikanan Pantai (PPP) Tegalsari, Kota Tegal, Provinsi Jawa Tengah. Penelitian dilakukan secara acak pada perairan di sekitar pelabuhan yang terdapat spot tumpahan minyak. Secara geografis posisi koordinat lokasi pengambilan sampel dapat dilihat pada tabel 3 berikut: 
Tabel 3. Posisi Koordinat Pengambilan Sampel

\begin{tabular}{ccc}
\hline \multirow{2}{*}{ Titik } & \multicolumn{2}{c}{ Posisi Koordinat } \\
\cline { 2 - 3 } & Lintang Selatan & Bujur Timur \\
\hline 1 & $06^{0} 51^{\prime} 3.30^{\prime \prime}$ & $109^{0} 07^{\prime} 44.12^{\prime \prime}$ \\
2 & $06^{0} 51^{\prime} 3.37^{\prime}$ & $109^{0} 07^{\prime} 46.17^{\prime}$ \\
3 & $06^{0} 51^{\prime} 3.42^{\prime}$ & $109^{0} 07^{\prime} 48.21^{\prime}$ \\
\hline
\end{tabular}

Sumber : Google Earth

Lokasi penelitian berada daerah Kota Tegal dan tidak jauh dari pusat kota. Lokasi tersebut sangat strategis dan dapat ditempuh dengan kendaraan pribadi ataupun angkutan umum. Selain itu lokasi pelabuhan berdekatan dengan Tempat Penjualan Ikan (TPI) Tegalsari, Kelurahan Tegalsari, Kecamatan Tegal Barat, Kota Tegal. Dimana pada lokasi tersebut memiliki banyak aktifitas kapal yang meliputi bongkar muat hasil tangkapan dengan intensitas yang cukup tinggi.

Sumber limbah minyak di perairan lokasi penelitian diduga berasal dari aktifitas kapal penangkap ikan yang bersandar di pelabuhan tersebut. Berdasarkan hasil pengamatan pada lokasi sampling, kapal-kapal yang berada di pelabuhan memproduksi dan membuang limbah minyak pada siang menjelang sore hari saat melakukan perawatan atau perbaikan kapal baik pada mesin kapal ataupun komponen lainnya. Olah gerak kapal pada saat keluar-masuk ke pelabuhan merupakan faktor utama terpecahnya limbah minyak pada perairan. Hal ini menyebabkan limbah minyak tersebut cepat tersebar dan mencemari seluruh bagian permukaan perairan. Pada umumnya, kapal-kapal penangkap ikan yang beroperasi di PPP Tegalsari, memiliki ukuran dibawah 100 GT yaitu berkisar antara 5 - 30GT, sehingga kapal tersebut masih belum dilengkapi dengan OWS. Hal ini merupakan faktor utama yang menyebabkan peningkatan produksi limbah minyak di periaran.

Berdasarkan pengamatan di lapangan selama kurang lebih satu minggu, untuk jumlah kapal yang beroperasi di PPP Tegalsari terhitung berkisar antara 30 hingga 50 unit kapal penangkap ikan aktif, terdiri dari beberapa jenis kapal dengan alat tangkap dan ukuran yang berbeda-beda. Dapat dilihat betapa tinggi dan padatnya aktifitas kapal yang berlabuh di PPP Tegalsari.

Luas lahan di PPP Tegalsari yaitu mencapai 16,3 Ha dengan pemanfaatan lahan untuk fasilitas fungsional, bangunan pemerintah dan kepentingan umum $\pm 13,3$ Ha. Luas kolam PPP Tegalsari yaitu mencapai $190.000 \mathrm{~m}^{2}$, Sedangkan menurut perhitungan berdasarkan data yang diperoleh di lapangan, luas kolam pelabuhan yang telah digunakan adalah $32.400 \mathrm{~m}^{2}=3,24 \mathrm{Ha}$ dengan kedalaman $4 \mathrm{~m}$. Kolam dapat menampung kapal sebanyak 142 unit kapal sekaligus yang berukuran 5 - 30 GT (Nurdyana et al., 2013).

Konstruksi atau kerangka dari alat Oil Skimmer dapat dilihat pada gambar 3 berikut ini :

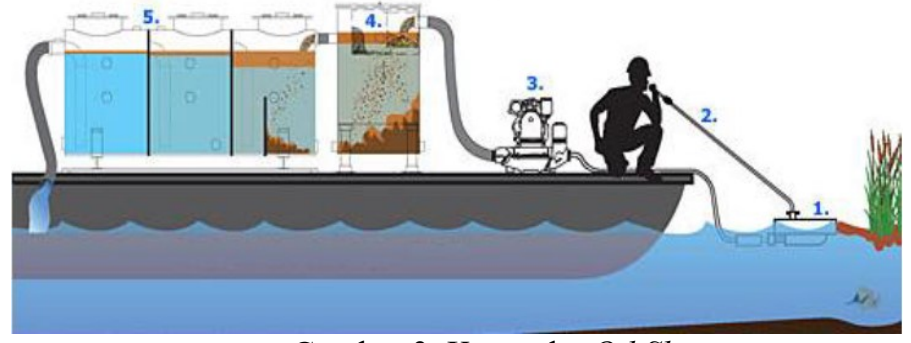

Gambar 3. Kerangka Oil Skimmer

Keterangan :

1. Skimmer

2. Tongkat Pengontrol dan penghisap

3. Pompa penghisap

4. Tangki penampung sementara

5. Tangki penyaring kedua

(Sumber : BBPPI Semarang, 2016).

Oil skimmer dioperasikan secara langsung pada titik atau spot yang terdapat tumpahan minyak di perairan. Seperti pada gambar 8 diatas, contoh air akan dihisap oleh skimmer menggunakan tongkat skimmer untuk mengarahkan laju dan olah gerak skimmer dalam menghisap contoh air . Contoh air akan terhisap oleh pompa penghisap dan masuk ke dalam tangki penampung sementara pada kapal melalui pipa pada skimmer. Setelah tangki terisi penuh, maka secara otomatis contoh air akan masuk ke dalam tangki penyaring secara bertahap hingga partikel minyak benar-benar terpisah dengan air dan tertinggal pada tangki. Contoh air yang telah terpisah dengan limbah minyak akan dibuang secara langsung ke perairan melalui pipa pada bagian belakang kapal.

Hasil pengukuran kandungan minyak pada pengambilan sampel di setiap titik pengamatan dapat dilihat pada Tabel 4 sebagai berikut : 
Tabel 4. Hasil Uji Kandungan Minyak Total Sebelum dan Sesudah Diolah Dengan Oil skimmer

\begin{tabular}{|c|c|c|c|c|c|}
\hline \multirow[t]{2}{*}{ Titik } & \multirow{2}{*}{$\begin{array}{c}\text { Waktu } \\
\text { Sampling }\end{array}$} & \multirow{2}{*}{$\begin{array}{c}\text { Ulangan } \\
\text { Ke- }\end{array}$} & \multicolumn{2}{|c|}{$\begin{array}{c}\text { Kandungan Minyak } \\
(\mathrm{mg} / \mathrm{l})\end{array}$} & \multirow{2}{*}{$\begin{array}{c}\text { Efektivitas } \\
(\%)\end{array}$} \\
\hline & & & Sebelum & Sesudah & \\
\hline \multirow{4}{*}{1} & \multirow{2}{*}{ Pagi } & 1 & 1128 & 192 & 83 \\
\hline & & 2 & 484 & 158 & 67 \\
\hline & \multirow{2}{*}{ Siang } & 1 & 324 & 206 & 36 \\
\hline & & 2 & 260 & 136 & 48 \\
\hline \multicolumn{2}{|c|}{ Rata-rata } & & 549 & 173 & 58.5 \\
\hline \multicolumn{2}{|c|}{ Standar Deviasi } & & 397,329 & 31,8538 & \\
\hline \multirow{4}{*}{2} & \multirow{2}{*}{ Pagi } & 1 & 9496 & 77 & 99 \\
\hline & & 2 & 5664 & 90 & 98 \\
\hline & \multirow{2}{*}{ Siang } & 1 & 1020 & 63 & 94 \\
\hline & & 2 & 4000 & 135 & 97 \\
\hline \multicolumn{2}{|c|}{ Rata-rata } & & 5045 & 91.25 & 97 \\
\hline \multicolumn{2}{|c|}{ Standar Deviasi } & & 3534,93 & 31,1809 & \\
\hline \multirow{4}{*}{3} & \multirow{2}{*}{ Pagi } & 1 & 3992 & 164 & 96 \\
\hline & & 2 & 3636 & 108 & 97 \\
\hline & \multirow{2}{*}{ Siang } & 1 & 2967 & 146 & 95 \\
\hline & & 2 & 2976 & 114 & 96 \\
\hline \multicolumn{2}{|c|}{ Rata-rata } & & 3392.75 & 133 & 96 \\
\hline \multicolumn{3}{|c|}{ Standar Deviasi } & 507,679 & 26,5581 & \\
\hline
\end{tabular}

Sumber : Penelitian September 2016

Pada tabel 4, menunjukan bahwa rata-rata nilai kandungan minyak sebelum diolah dengan oil skimmer sangat tinggi yaitu berkisar antara $549 \mathrm{mg} / \mathrm{l}$ sampai $5045 \mathrm{mg} / \mathrm{l}$, sedangkan setelah diolah dengan oil skimmer menjadi jauh lebih rendah yaitu berkisar antara $91.25 \mathrm{mg} / \mathrm{l} \mathrm{sampai} 173 \mathrm{mg} / \mathrm{l}$. Nilai rata-rata prosentase efektifitas berkisar antara 58.5 $\%$ sampai $97 \%$.

Hasil perhitungan statistik uji $\mathrm{t}$ - berpasangan dapat dilihat pada Tabel 5 sebagai berikut : Tabel 5 . Perhitungan Uji t - Berpasangan

\begin{tabular}{|c|c|c|c|c|c|c|c|c|}
\hline \multicolumn{9}{|c|}{ Paired Samples Test } \\
\hline & \multicolumn{5}{|c|}{ Paired Differences } & \multirow[b]{3}{*}{$\mathrm{T}$} & \multirow[b]{3}{*}{$\mathrm{df}$} & \multirow{3}{*}{$\begin{array}{l}\text { Sig. (2- } \\
\text { tailed) }\end{array}$} \\
\hline & \multirow[b]{2}{*}{ Mean } & \multirow{2}{*}{$\begin{array}{c}\text { Std. } \\
\text { Deviation }\end{array}$} & \multirow{2}{*}{$\begin{array}{l}\text { Std. Error } \\
\text { Mean }\end{array}$} & \multicolumn{2}{|c|}{$\begin{array}{l}95 \% \text { Confidence } \\
\text { Interval of the } \\
\text { Difference }\end{array}$} & & & \\
\hline & & & & Lower & Upper & & & \\
\hline $\begin{array}{ll}\text { Pair } 1 & \begin{array}{l}\text { Sebelum - } \\
\text { Setelah }\end{array}\end{array}$ & 2863.167 & 2722.458 & 785.906 & 1133.399 & 4592.934 & 3.643 & 11 & .004 \\
\hline
\end{tabular}

Sumber : Penelitian September 2016

Pada Tabel 5, didapatkan nilai t (sig. 2 tailed) yaitu 0,004, maka Ho ditolak. Karena nilai $\mathrm{t} \leq 0.05$, hal ini berarti kandungan minyak sebelum diolah dengan oil skimmer memiliki perbedaan dengan kandunganminyak setelah diolah dengan oil skimmer. Sehingga kesimpulan dari uji t berpasangan yaitu kedua sampel memiliki perbedaan yang sangat signifikan antara kandungan minyak sebelum diolah dengan Oil Skimmer dan setelah diolah dengan Oil Skimmer.

Data hasil uji kandungan minyak pada tabel 4, menunjukkan rata-rata nilai kandungan minyak pada titik 1 sebelum diolah dengan Oil Skimmer yaitu sebesar $549 \mathrm{mg} / \mathrm{l}$ dan setelah diolah dengan Oil Skimmer menjadi $173 \mathrm{mg} / \mathrm{l}$ dengan rata-rata prosentase efektivitas sebesar 58,5\%. Data tersebut merupakan data yang paling rendah dibandingkan dengan hasil uji minyak pada titik 2 dan titik 3, dengan rata-rata prosentase efektivitas pada titik 2 yaitu $97 \%$ dan pada titik 3 yaitu $96 \%$.

Berbeda dengan nilai kandungan minyak pada titik 2 dan titik 3 yang bersifat normal. Pada titik 2 dan titik 3 , nilai kandungan minyak sebelum diolah rata-rata berkisar hingga ribuan yaitu $5045 \mathrm{mg} / \mathrm{L}$ dan 3392,75 mg/l, sedangkan pada titik 1 hanya berkisar berkisar ratusan yaitu $549 \mathrm{mg} / \mathrm{L}$. Hal tersebut memiliki selisih perbedaan yang cukup jauh. Secara keseluruhan pada sampel setelah diolah dengan oil skimmerpada titik 1, 2 dan 3 bersifat normal, karena rentan selisih nilainya tidak begitu jauh, yaitu $173 \mathrm{mg} / 1,91,25 \mathrm{mg} / \mathrm{l}$, dan $133 \mathrm{mg} / \mathrm{l}$. Dapat diasumsikan bahwa data yang tidak normal secara keseluruhan terjadi pada sampel sebelum diolah dengan oil skimmer pada titik 1.

Hal ini dikarenakan, pada titik 1, sampel yang terserap oleh skimmer ke dalam tangki penampung sebelum diolah dengan OWS (Oily Water Separator) memiliki perbandingan antara volume limbah minyak dan volume air yang tercampur lebih banyak dibandingkan volume limbah minyak itu sendiri. Hal tersebut dikarenakan sampel yang ada di perairan telah tercecer dan menyebar, sehingga sampel minyak yang terserap lebih sedikit dibanding air. Bahan toksik 
di perairan juga akan demikian mengalami proses pengenceran dan dispersi sehingga kosentrasinya menurun secara berkala (Hutagalung, 1991 dalam Haryanto et al., 2013). Sehingga pada saat dilakukan pengujian minyak, sangat berpengaruh terhadap nilai akhir dalam penentuan nilai kandungan minyak. Lapisan minyak yang telah terpisah lapisan air saat proses destilasi, cenderung lebih sedikit. Hal tersebut berbeda dengan hasil output nya yang bersifat tetap, dimana pengujian minyak pada sampel setelah diolah dengan oil skimmer, cenderung normal. Hal ini dikarenakan limbah minyak telah dipisahkan oleh OWS dan ditampung dalam tangki penampung minyak, sehingga sisa kandungan minyak yang terbawa telah tersuspensi bersama dengan volume air sampel. Menurut Putra dan Ardian (2014), dalam penelitiannya menyatakan bahwa semakin besar limbah minyak yang tercampur dengan air, maka semakin tinggi pula nilai atau kadar kandungan minyak tersebut, dan semakin tinggi pula efek pencemarannya terhadap lingkungan.

Nilai standar deviasi pada sampel sebelum dan setelah diolah dengan oil skimmer pada titik 1 yaitu 397,329 $\mathrm{mg} / \mathrm{l}$ dengan rata-rata $549 \mathrm{mg} / \mathrm{l}$, dan $31.8538 \mathrm{mg} / \mathrm{l}$ dengan rata-rata $173 \mathrm{mg} / \mathrm{l}$. Pada titik 2 yaitu 3534,93 mg/l dengan rata-rata $5045 \mathrm{mg} / \mathrm{l}$, dan pada sampel setelah yaitu $31.1809 \mathrm{mg} / \mathrm{l}$ dengan rata-ratanya $91,25 \mathrm{mg} / \mathrm{l}$, sedangkan pada titik 3 yaitu $507,679 \mathrm{mg} / 1$ dengan rata-rata $3392,75 \mathrm{mg} / 1$, dan $26,5581 \mathrm{mg} / 1$ dengan nilai rata-ratanya $133 \mathrm{mg} / \mathrm{l}$.

Pada sampel sebelum proses, nilai standar deviasi lebih rendah dari nilai rata-rata, artinya dengan standar deviasi lebih besar dibandingkan nilai rata-rata, maka nilai rata-rata sebelum proses Oil skimmer merupakan representasi yang buruk dari keseluruhan data. Sedangkan dengan nilai standar deviasi lebih kecil dibandingkan ratarata, maka nilai rata-rata pada sampel setelah proses Oil skimmer dapat digunakan sebagai representasi dari keseluruhan data (Setiawan et al., 2014).

Berdasarkan nilai kandungan minyak yang diperoleh antara sebelum dan setelah diolah dengan oil skimmer, memilik tingkat efektivitas yang tinggi hampir 99\%. Namun kandungan minyak pada sampel setelah diolah dengan oil skimmer masih berada diatas baku mutu yang telah ditetapkan, yaitu $15 \mathrm{mg} / \mathrm{l}$. Sehingga perlu adanya pengkajian lebih lanjut untuk menurunkan nilai kandungan minyak setelah diolah dengan oil skimmer agar nilai yang diperoleh berada di bawah baku mutu standar yang telah ditetapkan.

Menurut Suyasa dan Arsa (2013), menyatakan dalam penelitiannya bahwa Efektifitas perlakuan aerasi terhadap penurunan kadar minyak meningkat seiring dengan bertambahnya waktu. perlakuan aerasi merupakan tahap awal yang cukup efektif dalam mengolah air limbah. Akan tetapi kadar minyak masih berada diatas baku mutu. Oleh sebab itu untuk menurunkan kadar minyak air limbah agar sesuai atau berada di bawah baku mutu maka setelah perlakuan flotasi air limbah kemudian diolah dengan lumpur aktif.

Respon setiap organisme terhadap limbah minyak diperairan limbah minyak diperairan berbeda-beda. Setiap spesies memiliki kemampuan berbeda dalam menerima dan hidup dalam kondisi tercemar minyak dengan kadar tertentu. Keberadaan organisme penting di dalam perairan sangatlah vital, seperti alga atau tumbuhan hijau lain sebagai produsen utama dalam perairan. Menurut Setiawan et al., (2014), menyatakan bahwa penghambatan pertumbuhan alga dan penurunan populasi alga terjadi karena interaksi antar alga dan cemaran minyak. Hal tersebut karena setiap organisme hidup mempunyai batas toleran masing-masing yang masih dapat diterimanya, apabila nilai tersebut terlewati maka organisme tersebut akan mulai terganggu. Pada tingkatan yang sudah maksimal dapat mematikan organisme tersebut termasuk mikroalga, seperti Chlorella vulgaris, Ulva dan yang lainnya. Peran alga sebagai produsen primer menjadi vital baik dari fungsi sebagai penghasil oksigen dari proses fotosintesisnya ataupun karena bisa menyebabkan biomagnifikasi apabila alga yang sudah terkontaminasi minyak dikonsumsi konsumen sampai rantai tertinggi, maka besar konsentrasi toksiknya akan terus meningkat serta tidak menutup kemungkinan dapat mengenai manusia sebagai konsumen tingkat tinggi dalam rantai makanan.

Menurut Rongcheng et al. (1986) dalam Setiapermana et al. (1995), minyak memiliki pengaruh terhadap reproduksi seksual dan formasi Auxospora dalam diatom. Dalam berbagai penelitian pada daerah beriklim sedang, didapatkan bahwa kandungan minyak dalam air laut dengan konsentrasi diatas $300 \mathrm{mg} / \mathrm{L}$ secara nyata menghalangi penyerapan heterotropik dan mineralisasi glukosa.

Nilai efektivitas ditentukan berdasarkan perbandingan atau selisih antara volume awal dan volume akhir atau dalam hal ini yaitu selisih antara nilai kandungan minyak sebelum (awal) dan kandungan minyak sesudah (akhir) proses Oil skimmer.

Perbedaan kandungan minyak dan lemak pada sampel sebelum dan setelah diolah dengan Oil skimmer yang didukung dengan hasil perhitungan nilai efektivitas berkisar antara $89 \%$ sampai $99 \%$, data tersebut sangat tinggi bahkan hampir mendekati $100 \%$ meski masih ada beberapa sampel yang memliki nilai efektivitas dibawah kisaran tersebut yaitu dengan nilai $36 \%$ dan $48 \%$, namun tidak memberikan pengaruh yang besar dan berarti pada data lainnya. Hal tersebut menunjukan penggunaan Oil skimmer dalam mereduksi kandungan limbah minyak pada kasus tumpahan minyak di periaran sangat efektif berdasarkan nilai dan perhitungan efektivitas dari data yang ada. Hal ini dikarenakan sudah ada proses pemisahan antara minyak dan air didalam OWS (Oil Water Separator) sebagai alat atau media pemisah yang dapat menugrangi kandungan minyak dari limbah cair minyak di peraiaran (Cahyani, 2011). Menurut (Sudigdo, 2004 dalam Wibowo, 2014) Efektifitas Oil skimmer sebagai alat pemisah limbah cair berminyak merupakan nilai perbandingan antara volume minyak akhir dengan volume minyak awal. 


\section{KESIMPULAN}

Kesimpulan yang dapat ditarik dari penelitian ini adalah sebagai berikut :

1. Nilai kandungan minyak limbah cair pada perairan Pelabuhan Perikanan Pantai (PPP) Tegalsari, Kota Tegal sebelum diproses dengan Oil skimmer berkisar antara $260 \mathrm{mg} / \mathrm{L}$ sampai $9496 \mathrm{mg} / \mathrm{L}$, sedangkan setelah proses Oil skimmer menjadi jauh lebih rendah yaitu berkisar antara $63 \mathrm{mg} / \mathrm{L}$ sampai $206 \mathrm{mg} / \mathrm{L}$;

2. Rata-rata prosentase nilai efektifitas penggunaan Oil skimmer dalam menangani tumpahan minyak limbah cair di perairan Pelabuhan Perikanan Pantai (PPP) Tegalsari, Kota Tegal yaitu berkisar antara 58.5\% sampai 97\%.

\section{UCAPAN TERIMA KASIH}

Ucapan terima kasih penulis tujukan kepada Prof. Dr. Ir. Sahala Hutabarat, M.Sc, sebagai tim penguji dalam karya ilmiah ini, dan kepada Tri Wahyu Wibowo S.Pi, atas bimbingan dan arahan selama di lapangan.

\section{DAFTAR PUSTAKA}

BPS. 2013. Jumlah Produksi dan Nilai Produksi Perikanan Laut per Triwulan di Kota Tegal Tahun 2013. Badan Pusat Statistik, Kota Tegal.

BSN. 2008. SNI 6989.59:2008 Tentang Air dan Air Limbah - Bagian 59 : Metode Pengambilan Contoh Air Limbah. Badan Standarisasi Nasional, Jakarta.

2004. SNI 06-6989.10-2004 Tentang Air dan Air Limbah - Bagian 10 : Cara Uji Minyak dan Lemak Secara Gravimetri. Badan Standarisasi Nasional, Jakarta.

Cahyani, Maria Febri. 2011. Rancang Bangun Blige Oily Water Separator Berbasis Elektrokimia. Fakultas Teknologi Kelautan, Institut Teknologi Sepuluh Nopember, Surabaya.

Haryanto, K., M. F. Samawi dan A. Haris. 2013 Akumulasi Logam Berat Pb pada Rangka dan Polip Karang Lunak Sinularia polydactyla. Jurnal Ilmu Kelautan dan Perikanan, 23(1) : 1 - 7.

Nurdyana, E,. Rosyid. A., dan Boesono, H. 2013. Strategi PemanfaatnFasilitas Dasar dan Fungsional Pelabuhan Perikanan Pantai (PPP) Tegalsari Kota Tegal. Unniversitas Diponegoro. Semarang.

Nuryatini, dan Edi Iswanto Wiloso. 2010. Uji Metode Analisis Minyak Terdispersi Dalam Air. Jakarta : Jurnal Teknologi Indonesia, 33 (1) : 20 - 26.

Putra, D., S., dan Ardian Putra. 2014. Analisis Pencemaran Limbah Cair Kelapa Sawit Berdasarkan Kandungan Logam, Konduktivitas, TDS dan TSS. Jurnal Fisika Unand, 3(2).

Republik Indonesia. 1999. Peraturan Pemerintah No. 19 Tahun 1999 Tentang Pengendalian Pencemaran Dan/Atau Perusakan Laut. Sekretariat Negara, Jakarta.

2007. Peraturan Pemerintah No. 4 Tahun 2007 Tentang Baku Mutu Air Limbah Bagi Usaha Dan/Atau Kegiatan Minyak dan Gas serta Minyak Bumi. Sekretariat Negara, Jakarta.

Setiapermana, D., H.W.Y. Wuayanta, R. Widodo dan A. Damar. 1995. Efek Minyak Mentah Attaka 39,60 API Terhadap Parameter Fotosintetik Fitoplankton dalam Suatu Mesokosm. Jurnal Oseaonologi dan Limnologi. 28 : 37 -63 .

Setiawan, T.E., Haeruddin, dan Churun 'Ain. 2014. Efisiensi Penggunaan Oil Water Separator pada Kapal Penangkap Ikan untuk Pencegahan Pencemaran Minyak di Laut (Studi Kasus KM. Mantis) di BBPPI Semarang. Jurnal Perikanan dan Ilmu Kelautan. 3:112-120.

Soenarno, Sri Murni. 2011. Pengolahan Limbah IWF Peduli Pelestarian Alam. Jakarta.

Sulistyono. 2010. Dampak Tumpahan Minyak (Oil Spill) di Perairan Laut pada Kegiatan Industri Migas dan Metode Penanggulangannya. Jurnal Forum Teknologi. 3(1).

Suyasa, I W.B., dan Arsa, I M. 2013. Penurunan Kadar Minyak dan COD Air Limbah Operasional Pembangkit Listrik Dengan Flotasi dan Lumpur Aktif. Universitas Udayana. Denpasar, Bali.

Wibowo, Tri Wahyu. 2014. Uji Performansi Alat Pemisah Limbah Cair Berminyak (Oily Water Separator) untuk Kapal Perikanan dalam Skala Laboratorium. Fakultas Perikanan dan Ilmu Kelauatan Universitas Diponegoro, Semarang. [Skripsi]. 